\title{
Occupational exposure to polycyclic aromatic hydrocarbons and risk of prostate cancer
}

\author{
Christine Barul ${ }^{1}$ and Marie-Elise Parent ${ }^{1,2,3^{*}}$ (1)
}

\begin{abstract}
Background: Several industries entailing exposure to polycyclic aromatic hydrocarbons (PAHs) are known or suspected carcinogens. A handful of studies have assessed the role of PAHs exposure in prostate cancer risk, but none has examined tumor aggressiveness or the influence of screening practices and detection issues. We aimed to examine the association between lifetime occupational exposure to PAHs and prostate cancer risk.
\end{abstract}

Methods: Detailed work histories were collected from 1,929 prostate cancer cases (436 aggressive) and 1,994 controls from Montreal, Canada (2005-2012). Industrial hygienists applied the hybrid expert approach to assign intensity, frequency and certainty of exposure to benzo[a]pyrene, PAHs from wood, coal, petroleum, other sources, and any source, in each job held. Odds ratios (ORs) for prostate cancer risk associated with lifetime PAHs exposure, adjusted for age, ancestry, education, lifestyle and occupational factors, and 95\% confidence intervals (Cl), were estimated using unconditional logistic regression.

Results: After restriction to probable and definite exposures, and application of a 5-year lag, no clear association emerged for any of the PAHs, although small excesses in risk were apparent with 5-year increments in exposure to PAHs from wood ( $\mathrm{OR}=1.06,95 \% \mathrm{Cl} 0.95$ to 1.18$)$. While analyses by cancer aggressiveness suggested no major differences, some elevated risk of high-grade cancer was observed for exposure to PAHs from wood $(\mathrm{OR}=1.37,95 \% \mathrm{Cl} 0.65$ to 2.89), frequently occurring among firefighters.

Conclusion: Findings provide weak support for an association between occupational exposure to PAHs from wood and prostate cancer risk.

Keywords: Prostate, Polycyclic aromatic hydrocarbons, Tumor, Occupational health, Case-control study

\section{Introduction}

In the next two decades, around 11 million news cases of prostate cancer will be diagnosed worldwide [1]. The rising prostate cancer burden prompts for the identification of modifiable risk factors and primary preventive interventions [2]. Some thirty percent of prostate cancers are

\footnotetext{
*Correspondence: marie-elise.parent@inrs.ca

${ }^{1}$ Epidemiology and Biostatistics Unit, Centre Armand-Frappier Santé Biotechnologie, Institut national de la recherche scientifique, Université du Québec, 531 Boulevard des Prairies, Laval, Québec H7V 1B7, Canada Full list of author information is available at the end of the article
}

aggressive, but health issues associated with diagnosis and treatment of the non aggressive form of the disease remain of important significance.

The descriptive epidemiology of cancer of the prostate, a hormone-dependant organ [3], strongly suggests that non-genetic influences are at play [4-6]; genetic factors would only explain about one third of familial risk. An increasing attention is paid to the role of environmental exposures, some of which showing deleterious toxicological effects such as hormone-disruption or genotoxicity $[7,8]$. Polycyclic aromatic hydrocarbons (PAHs) are a family of over 100 chemicals, generally found in complex original author(s) and the source, provide a link to the Creative Commons licence, and indicate if changes were made. The images or other third party material in this article are included in the article's Creative Commons licence, unless indicated otherwise in a credit line to the material. If material is not included in the article's Creative Commons licence and your intended use is not permitted by statutory regulation or exceeds the permitted use, you will need to obtain permission directly from the copyright holder. To view a copy of this licence, visit http://creativecommons.org/licenses/by/4.0/. The Creative Commons Public Domain Dedication waiver (http://creativeco mmons.org/publicdomain/zero/1.0/) applies to the data made available in this article, unless otherwise stated in a credit line to the data. 
mixtures occurring naturally in the environment or resulting from the incomplete combustion or pyrolysis of various organic materials [9]. In the general population, exposure to PAHs mostly occurs through tobacco smoking and from the cooking of food at high temperatures. The workplace remains a major source of PAHs exposure and several industries entailing high exposure to mixtures of PAHs are known or suspected carcinogens to humans [10].

PAHs' ability to form DNA adducts through their ultimate metabolites interactions with DNA [11] or their antiestrogenic properties [12] may be involved in the initiation or promotion of prostate cancer. Benzo $[a]$ pyrene is the sole PAH having been classified to date as carcinogenic to humans by the International Agency for Research on Cancer [10]. Only a handful of studies have examined the link between occupational exposure to PAHs and prostate cancer risk, with inconclusive findings. A cohort study including 1,386 incident cases investigating this association reported null findings with regards to overall exposure to PAHs [13]. Three small case-control studies have classified PAHs exposure according to their material sources [14-16]. One reported no association with ever exposure to PAHs [15], while positive associations with lower levels of exposure to benzo[a]pyrene [16], PAHs from coal $[14,16]$ and PAHs from other sources [16] emerged in the two others. No previous study has considered prostate cancer aggressiveness or detection issues that may obscure associations with exposure.

We previously reported that some industries (i.e., forestry and logging) and occupations (i.e., firefighters, gasoline station attendants) were at higher risk of prostate cancer [17]. By pointing to a potential deleterious role of occupational exposure to PAHs, these findings motivated the current investigation. We present here the largest, and one of the rare epidemiologic studies to date, evaluating the role of occupational exposure to PAHs overall, and according to various sources, in prostate cancer risk.

\section{Methods}

\section{Study design}

The present work emanates from the Prostate Cancer \& Environment Study (PROtEuS), a large population-based case-control study conducted in Montreal, Canada in 2005-2012, and specifically designed to evaluate the role of occupational exposures. Details have been reported elsewhere $[18,19]$. In order to comply with institutional regulations and insure comprehensive population coverage at recruitment, the study base was restricted to men who referred or would be expected to refer to a French hospital for a prostate cancer diagnosis. All subjects were residents of the Greater Montreal area. Incident prostate cancer cases, aged $\leq 75$ years, histologically-confirmed, were identified through Montreal hospitals serving the French-speaking population, thereby covering $80 \%$ of all prostate cancer diagnoses in the area during the study period. Concurrently, controls were randomly selected from the continually-updated electoral list of Frenchspeaking men, and frequency-matched to cases on age ( \pm 5 years). Overall, $79 \%$ of cases $(n=1,937)$ and $56 \%$ of eligible controls $(n=1,994)$ agreed to participate in the study. Refusals (86\%) were the main reason for nonparticipation. Ethics committees of all participating institutions approved the study protocol and all subjects provided written informed consent.

\section{Data collection}

In-person interviews, conducted mostly at the home of participants, collected information on sociodemographic and lifestyle characteristics, and a complete occupational history. A few interviews (3\% for cases, $4 \%$ for controls) were conducted with proxy respondents, mainly the spouses.

A detailed description was elicited for each job held for at least 2 years, including tasks and use of products, equipment, and protective measures. In addition, specialized questionnaires $(n=32)$, probing for specific task details, were administered for complex occupations lasting at least 5 years. Occupations and industries were coded according to Canadian classifications [20, 21].

Gleason scores, reflecting tumor grades, were extracted from pathology reports. These have been shown to be a good proxy for disease progression [22] and were used to define cancer severity. Tumor grades were recorded from diagnostic biopsies (main analyses) as well as from prostatectomy, when available.

\section{Exposure assessment of PAHs}

For each job, exposure to 313 agents, including PAHs, was assigned. PAH assessments included benzo[a]pyrene, as well as other PAHs grouped according to their sources, i.e., wood, petroleum, coal, or other sources (such as resulting from the pyrolysis products of plastic, paint, rubber, food or other organic compounds). Exposure to PAHs from any source was derived by aggregating the information from individual sources.

The hybrid expert-based assessment approach, described previously [23], was used to assign exposures based on the 16,065 detailed job descriptions. By providing clearer guidelines for coding, the hybrid expert-based approach was recently developed to improve on efficiency, comprehensiveness and transparency of assignments, and greater coherence between experts [23]. Basically, it makes use of job-exposure profiles summarizing expert evaluations from previous studies, complemented with comments on coding specific exposure 
circumstances, which together with the subjects' job descriptions, guide experts in their assignments.

For each exposure, experts provided three semi-quantitative indices of exposure: the degree of confidence that the exposure actually occurred in the job (possible, probable, definite), the frequency of exposure $(<5 \%$, $5 \%-30 \%,>30 \%-90 \%,>90 \%$ of usual workweek) and the relative intensity of exposure (low, medium, high) with non-exposure representing levels encountered in the general environment. Two hygienists, blinded to the case-control status of participants, carried out independent assessments; conflicting codings were resolved by consensus.

Exposure to benzo[a]pyrene was automatically assigned when other specific exposures (assigned by experts) occurred, conditional on their concentration, reliability, and frequency of exposure within the job, according to an algorithm devised by the team. The main chemical generators of benzo $[a]$ pyrene were asphalt, coal and wood combustion products, coal and wood soot, tar and pitch, creosote, diesel and leaded engine emissions, ink formulation oils, mineral-based oil and greases, rubber pyrolysis products, and textile oils.

\section{Statistical analysis}

For each PAH exposure, frequency intervals were recoded according to their median values. The three intensity levels were transformed into values of 1,5 and 25 , respectively, to better reflect the quantitative levels underlying the hygienists' assignments [24].

Several exposure metrics were used, built from probable or definite exposures, and applying a 5-year lag: (i) ever exposure; (ii) duration of exposure, summing all exposed job periods over the course of the career; and (iii) cumulative exposure (CE) calculated as follows:

$$
\mathrm{CE}=\sum_{i=1}^{k}\left(\mathrm{I}_{i} \times \mathrm{F}_{i} \times \mathrm{D}_{i}\right)
$$

where $i$ represented the $i^{\text {th }}$ job held, $k$ was the total number of jobs held, $\mathrm{I}_{i}$ was the intensity of exposure in the job $i, \mathrm{~F}_{i}$ the frequency of exposure in the job $i$ and $\mathrm{D}_{i}$ the duration of the job $i$ in years.

Odds ratios (ORs) and their corresponding 95\% confidence intervals $(\mathrm{CI})$ were calculated using unconditional logistic regression, modelling the association between exposure to each PAH and prostate cancer risk. Polytomous regression models were applied to assess risk according to cancer aggressiveness. Low-grade tumors (non-aggressive) were those with Gleason scores $\leq 6$ or 7 [with 3 as primary and 4 as secondary pattern] while the high-grade ones (aggressive) were those with scores $\geq 8$ or 7 [with 4 as primary and 3 as secondary pattern] [25].
Heterogeneity in risk between the two grades was investigated with the Wald test.

In all analyses, the reference category included men who had never been occupationally exposed to any of the PAHs under investigation, those whose assignments to PAHs across all jobs had only been judged as possible, and those who had been exposed to PAHs only within the 5 years preceding the diagnosis/interview.

The cumulative duration of exposure was expressed in terms of a 5-year range increase, after confirming linearity of the logit. We also categorized CE according to the $50^{\text {th }}$ and $75^{\text {th }}$ percentiles of the controls' distributions as follows: 'low exposure' $\left[<50^{\text {th }}\right.$ (excluding 0$\left.)\right]$, 'medium exposure' $\left[50^{\text {th }}\right.$ to $\left.75^{\text {th }}\right]$ and 'high exposure' for percentiles beyond the $75^{\text {th }}$. The medians of the CE categories were modelled as continuous variables allowing for the evaluation of dose-response relationships.

Sensitivity analyses were conducted to evaluate the robustness of our results: (1) restricting to controls who had been screened for prostate cancer in the two years preceding the interview, thereby reducing the likelihood of latent, undiagnosed cases, (2) applying a lag of 10 years; and (3) using other weights for the intensity of exposure $(1,3,9$ and $1,10,100$ instead of 1,5,25).

We also explored the timing of occupational exposure to PAHs over the course of the participants' careersthat is, whether the last job entailing exposure to PAHs had been held within the 10 years prior to the index date or further in the past.

All analyses were adjusted for factors that we identified as potential confounders with a causal directed acyclic graph: age at diagnosis/interview (continuous), ancestry (Sub-Saharan, Asian, French, Other European, Greater Middle Eastern, Latino, other), educational level (primary school or less, high school, college, university, other), alcohol drinking (drink-years), cigarette smoking (ever/never and cigarette-years), body mass index (in $\mathrm{kg} / \mathrm{m}^{2}:<18.50,18.50-24.99,25.00-29.99, \geq 30.00$ ), ever consumption of fried or grilled food, cumulative occupational exposure to benzene (non-exposed referents and tertiles of exposure), ever farming and workplace environmental tobacco smoke (non-exposed referents and tertiles of exposure).

The SAS software (version 9.4; SAS Institute, Cary, North Carolina) was used.

\section{Results}

In total, 1,924 prostate cancer cases and 1,989 controls contributed to the analyses. Most subjects were of French descent. Cases were more likely to have had primary school as their highest level of education. Seventy-six percent of controls had been screened for prostate cancer within 2 years of interview (Table 1). 
Additional file 1 lists some of the main occupations in which PAHs were assigned, according to exposure dimensions.

PAH-exposed occupations included firefighters, boilermakers, platers and structural-metal workers, timber cutting and related occupations, and printing press occupations. There was often concomitant exposure to benzo $[a]$ pyrene and other PAHs. Exposure to PAHs from wood mostly occurred at high intensity in firefighting occupations. Occupations in labouring and other elemental work (not elsewhere classified (n.e.c)), and timber cutting and related occupations were more occasionally exposed and at low intensity of exposure. Firefighting occupations nearly always entailed occupational exposure to PAHs, including benzo[a]pyrene, PAHs from wood, petroleum and other sources, but had no exposure to PAHs from coal.

Table 1 Selected characteristics of cases and controls, PROtEuS, Montreal, Canada, 2005-2012

\begin{tabular}{|c|c|c|}
\hline & $\begin{array}{l}\text { Prostate cancer cases } \\
n=1,924 \\
n(\%)\end{array}$ & $\begin{array}{l}\text { Controls } \\
n=1,989 \\
\mathrm{n}(\%)\end{array}$ \\
\hline \multicolumn{3}{|l|}{ Sociodemographic characteristics } \\
\hline \multicolumn{3}{|l|}{ Age (years) } \\
\hline Mean \pm sd & $63.6 \pm 6.8$ & $64.8 \pm 6.9$ \\
\hline \multicolumn{3}{|l|}{ Ancestry } \\
\hline Sub-Saharan & $129(6.7)$ & $89(4.5)$ \\
\hline Asian & $24(1.3)$ & $72(3.5)$ \\
\hline French & $1439(75.0)$ & $1243(62.5)$ \\
\hline Other European & $245(12.5)$ & $438(22.0)$ \\
\hline Greater Middle Eastern & $45(2.3)$ & $99(5.0)$ \\
\hline Latino & $29(1.5)$ & $31(1.6)$ \\
\hline Other & $1(0.1)$ & $3(0.2)$ \\
\hline Missing & $12(0.6)$ & $14(0.7)$ \\
\hline \multicolumn{3}{|l|}{ Educational level } \\
\hline Primary school of less & $448(23.3)$ & $427(21.4)$ \\
\hline High school & $571(29.6)$ & $576(29.0)$ \\
\hline College & $312(16.2)$ & $374(18.8)$ \\
\hline University & $588(30.6)$ & $610(30.7)$ \\
\hline Other & $5(0.3)$ & $2(0.1)$ \\
\hline \multicolumn{3}{|c|}{ Number of years since last prostate cancer screening (PSA and/or DRE) } \\
\hline$\leq 2.00$ years & $1904(99.0)$ & $1509(75.9)$ \\
\hline $2.01-5.00$ years & $1(0.1)$ & $152(7.5)$ \\
\hline$>5.00$ years & $0(0.0)$ & $81(4.1)$ \\
\hline Never screened & $3(0.2)$ & $191(9.6)$ \\
\hline Do not know if ever screened & $2(0.1)$ & $29(1.5)$ \\
\hline $\begin{array}{l}\text { Had screening but do not know } \\
\text { when }\end{array}$ & $14(0.6)$ & $27(1.4)$ \\
\hline
\end{tabular}

Abbreviations: PSA Prostate specific antigen, DRE Digital rectal examination
A larger range of occupations were exposed to PAHs from petroleum, including all aircraft mechanics and repairmen, and almost all industrial, farm and construction machinery mechanics and repairmen. Knitting occupations and printing press occupations were the most highly exposed occupations to PAHs from this source.

Exposure to PAHs from other sources also frequently occurred among motor-vehicle mechanics and repairmen, and sometimes among foremen of mechanics and repairmen (n.e.c) and boilermakers, platers and structural metal-workers.

Exposures to PAHs were weakly to moderately correlated with one another (see Additional file 2). The strongest correlations were found between PAHs from other sources and PAHs from petroleum $(r=0.33)$ and between PAHs from other sources and PAHs from wood $(r=0.27)$.

Benzo $[a]$ pyrene exposure occurred in most of jobs exposed to PAHs from wood (88\% of 143 exposed jobs) and to PAHs from coal (87\% of 172 exposed jobs). Contrastingly, jobs exposed to PAHs from other sources and to PAHs from petroleum less often entailed benzo[ $a]$ pyrene exposure (33\% of 384 exposed jobs and $23 \%$ of 2,399 exposed jobs, respectively).

Associations between occupational exposure to the different PAHs and risk of overall prostate cancer (notwithstanding tumor aggressiveness) are presented in Table 2. No clear association emerged for any of the PAHs and for any of the exposure metrics (ever, duration or cumulative exposure). However, a weak increase in risk was found in association with PAHs from wood for ever exposure $(\mathrm{OR}=1.24,95 \% \mathrm{CI} 0.79$ to 1.95$)$ and duration $(\mathrm{OR}=1.06$, $95 \%$ CI 0.96 to 1.18 , per 5 -year increment), and in the highest category of cumulative exposure $(\mathrm{OR}=1.54$, $95 \% \mathrm{CI} 0.60$ to 3.92 ), albeit without a dose-response pattern ( $\mathrm{p}$ for trend $=0.32$ ).

Firefighters were the occupational group the most often exposed to PAHs from wood. The OR for prostate cancer among the 40 firefighters exposed to PAHs from this source was 1.27 (95\%CI 0.61 to 2.67 ).

Table 3 shows associations between occupational exposure to PAHs and prostate cancer risk, by tumor aggressiveness. Risk estimates were generally close to unity for all of the PAHs studied. For aggressive prostate cancers, ORs of 1.28, 1.57 and 1.73 were found for the middle category of cumulative exposure to PAHs from any source, benzo[a]pyrene and PAHs from wood, respectively, but there was no exposure-response pattern. Some weak elevation in risk of high-grade cancers $(\mathrm{OR}=1.37,95 \% \mathrm{CI} 0.65$ to 2.89$)$ was apparent for ever exposure to PAHs from wood, based on 13 exposed cases. The ORs per 5-year increment of duration of exposure to PAHs from wood were 1.07 (95\%CI 0.96 to 
Table 2 Association Between Occupational Exposure to PAHs and Prostate Cancer Risk, PROtEuS, 2005-2012

\begin{tabular}{|c|c|c|c|c|}
\hline \multirow[t]{2}{*}{ Exposure } & \multirow[b]{2}{*}{ n Controls } & \multicolumn{3}{|c|}{ Prostate cancer } \\
\hline & & n Cases & $\mathrm{OR}^{\mathrm{a}}$ & $95 \% \mathrm{Cl}$ \\
\hline \multicolumn{5}{|l|}{ PAHs from any source } \\
\hline Never exposed & 1053 & 1009 & 1.00 & Ref \\
\hline Ever exposed & 573 & 560 & 1.00 & $(0.85,1.18)$ \\
\hline $\begin{array}{l}\text { Duration (per 5-year incre- } \\
\text { ment) }\end{array}$ & 573 & 560 & 1.00 & $(0.97,1.03)$ \\
\hline \multicolumn{5}{|l|}{ Cumulative exposure } \\
\hline $0.01-300.00$ & 303 & 293 & 0.99 & $(0.81,1.20)$ \\
\hline $300.01-1049.66$ & 125 & 130 & 1.03 & $(0.78,1.37)$ \\
\hline$>1049.66$ & 143 & 137 & 1.01 & $(0.76,1.33)$ \\
\hline $\mathrm{p}$ for trend & & & 0.93 & \\
\hline \multicolumn{5}{|l|}{ Benzo[a]pyrene } \\
\hline Ever exposed & 188 & 182 & 1.00 & $(0.78,1.26)$ \\
\hline $\begin{array}{l}\text { Duration (per 5-year incre- } \\
\text { ment) }\end{array}$ & 188 & 182 & 0.97 & $(0.92,1.03)$ \\
\hline \multicolumn{5}{|l|}{ Cumulative exposure } \\
\hline $0.01-226.95$ & 94 & 103 & 1.12 & $(0.81,1.55)$ \\
\hline $226.96-588.00$ & 42 & 42 & 1.03 & $(0.64,1.65)$ \\
\hline$>588.00$ & 52 & 37 & 0.73 & $(0.45,1.20)$ \\
\hline $\mathrm{p}$ for trend & & & 0.25 & \\
\hline \multicolumn{5}{|l|}{ PAHs from petroleum } \\
\hline Ever exposed & 516 & 514 & 1.01 & $(0.85,1.19)$ \\
\hline $\begin{array}{l}\text { Duration (per 5-year incre- } \\
\text { ment) }\end{array}$ & 516 & 514 & 1.01 & $(0.97,1.04)$ \\
\hline \multicolumn{5}{|l|}{ Cumulative exposure } \\
\hline $0.01-240.50$ & 266 & 278 & 1.06 & $(0.86,1.30)$ \\
\hline $240.51-901.00$ & 120 & 115 & 0.89 & $(0.67,1.20)$ \\
\hline$>901.00$ & 130 & 121 & 1.02 & $(0.76,1.37)$ \\
\hline $\mathrm{p}$ for trend & & & 0.93 & \\
\hline \multicolumn{5}{|l|}{ PAHs from wood } \\
\hline Ever exposed & 42 & 50 & 1.24 & $(0.79,1.95)$ \\
\hline $\begin{array}{l}\text { Duration (per 5-year incre- } \\
\text { ment) }\end{array}$ & 42 & 50 & 1.06 & $(0.95,1.18)$ \\
\hline \multicolumn{5}{|l|}{ Cumulative exposure } \\
\hline $0.01-450.00$ & 21 & 24 & 1.13 & $(0.60,2.16)$ \\
\hline $450.01-1732.50$ & 10 & 8 & 0.94 & $(0.33,2.66)$ \\
\hline$>1732.50$ & 11 & 18 & 1.54 & $(0.60,3.92)$ \\
\hline p for trend & & & 0.32 & \\
\hline \multicolumn{5}{|l|}{ PAHs from coal } \\
\hline Ever exposed & 57 & 57 & 0.97 & $(0.66,1.44)$ \\
\hline $\begin{array}{l}\text { Duration (per 5-year incre- } \\
\text { ment) }\end{array}$ & 57 & 57 & 0.95 & $(0.87,1.04)$ \\
\hline \multicolumn{5}{|l|}{ Cumulative exposure } \\
\hline $0.01-142.50$ & 30 & 36 & 1.15 & $(0.68,1.95)$ \\
\hline $142.51-546.25$ & 12 & 14 & 1.18 & $(0.52,2.70)$ \\
\hline$>546.25$ & 15 & 7 & 0.46 & $(0.18,1.17)$ \\
\hline $\mathrm{p}$ for trend & & & 0.12 & \\
\hline \multicolumn{5}{|l|}{ PAHs from other sources } \\
\hline Ever exposed & 88 & 91 & 0.95 & $(0.68,1.31)$ \\
\hline
\end{tabular}

Table 2 (continued)

\begin{tabular}{|c|c|c|c|c|}
\hline \multirow[t]{2}{*}{ Exposure } & \multirow[b]{2}{*}{ n Controls } & \multicolumn{3}{|c|}{ Prostate cancer } \\
\hline & & $\mathrm{n}$ Cases & $\mathrm{OR}^{\mathrm{a}}$ & $95 \% \mathrm{Cl}$ \\
\hline $\begin{array}{l}\text { Duration (per 5-year incre- } \\
\text { ment) }\end{array}$ & 88 & 91 & 1.01 & $(0.94,1.08)$ \\
\hline \multicolumn{5}{|l|}{ Cumulative exposure } \\
\hline $0.01-200.00$ & 44 & 41 & 0.89 & $(0.56,1.41)$ \\
\hline $200.01-725.00$ & 21 & 19 & 0.73 & $(0.37,1.42)$ \\
\hline$>725.00$ & 23 & 31 & 1.19 & $(0.62,2.30)$ \\
\hline $\mathrm{p}$ for trend & & & 0.59 & \\
\hline \multicolumn{5}{|c|}{$\begin{array}{l}\text { Abbreviations: OR Odds ratio, } P A H s \text { Polycyclic aromatic hydrocarbons, } \mathrm{Cl} \\
\text { Confidence interval }\end{array}$} \\
\hline
\end{tabular}

1.20 ) and 1.01 (95\%CI 0.85 to 1.21 ), for low- and highgrade tumors, respectively. For low-grade cancers, an OR of 1.74 (95\%CI 0.67 to 4.56 ) emerged for the highest cumulative exposure category, without apparent gradient in risk ( $\mathrm{p}$ for trend $=0.19$ ).

We investigated whether risks varied according to the timing of exposure to the various PAHs based on the last exposed job. There were marginal differences in risk estimates between recent ( $\leq 10$ years before index date) and remote ( $>10$ years) exposure to PAHs from any source, from petroleum and from other sources (data not shown). There were, however, suggestions of excess risks for remote exposure to benzo $[a]$ pyrene $(\mathrm{OR}=1.22,95 \% \mathrm{CI} 0.90$ to 1.64$)$, PAHs from wood $(\mathrm{OR}=1.27,95 \% \mathrm{CI} 0.75$ to 2.16$)$ and PAHs from coal $(\mathrm{OR}=1.28,95 \% \mathrm{CI} 0.78$ to 2.09$)$. Results were similar across aggressiveness categories, other than for PAHs from wood, where remote exposure appeared to be associated with some greater risk of high-grade cancers $(\mathrm{OR}=1.54,95 \% \mathrm{CI} 0.70$ to 3.39 , based on 12 exposed cases), as compared to low-grade ones $(\mathrm{OR}=1.18$, $95 \%$ CI 0.66 to 2.08 , based on 31 exposed cases).

In analyses focusing on firefighters exposed to PAHs from wood, the odds of low-grade cancer was 1.47 (95\%CI 0.69 to 3.16$)$ while that of high-grade cancer was 0.54 ( $95 \%$ CI 0.11 to 2.59 ).

It has been suggested that environment-induced prostate cancers could occur more often among men aged over 55 years at diagnosis, as younger cases would be more likely to result from genetic causes [26]. There was no interaction between age and PAHs exposures in the present study, but the number of subjects diagnosed at a younger age was low, which may have hampered our ability to detect an effect modification by age.

Tumor aggressiveness was ascertained from Gleason scores at diagnostic biopsy (all cases, main analysis). 
Table 3 Association Between Occupational Exposure to PAHs and Prostate Cancer Risk, by Tumor Aggressiveness, PROtEuS, 20052012

\begin{tabular}{|c|c|c|c|c|c|c|c|}
\hline \multirow[t]{2}{*}{ Exposure } & \multirow[b]{2}{*}{ n Co } & \multicolumn{3}{|c|}{$\begin{array}{l}\text { Low-grade prostate cancer } \\
n=1,488\end{array}$} & \multicolumn{3}{|c|}{$\begin{array}{l}\text { High-grade prostate cancer } \\
n=436\end{array}$} \\
\hline & & $\mathrm{nCa}$ & $\mathrm{OR}^{\mathrm{a}}$ & $95 \% \mathrm{Cl}$ & $\mathrm{nCa}$ & $\mathrm{OR}^{\mathrm{a}}$ & $95 \% \mathrm{Cl}$ \\
\hline \multicolumn{8}{|l|}{ PAHs from any source } \\
\hline Never exposed to any source & 1053 & 803 & 1.00 & Ref & 211 & 1.00 & Ref \\
\hline Ever exposed & 573 & 420 & 0.97 & $(0.81,1.17)$ & 142 & 1.08 & $(0.83,1.42)$ \\
\hline Duration (per 5-year increment) & 573 & 420 & 0.99 & $(0.96,1.03)$ & 142 & 1.01 & $(0.97,1.07)$ \\
\hline \multicolumn{8}{|l|}{ Cumulative exposure } \\
\hline $0.01-300.00$ & 303 & 221 & 0.96 & $(0.78,1.19)$ & 73 & 1.06 & $(0.78,1.46)$ \\
\hline $300.01-1049.66$ & 125 & 91 & 0.95 & $(0.70,1.30)$ & 39 & 1.28 & $(0.84,1.95)$ \\
\hline$>1049.66$ & 143 & 108 & 1.02 & $(0.75,1.39)$ & 30 & 0.93 & $(0.58,1.47)$ \\
\hline $\mathrm{p}$ for trend & & & 0.86 & & & 0.79 & \\
\hline \multicolumn{8}{|l|}{ Benzo[a]pyrene } \\
\hline Ever exposed & 188 & 136 & 0.98 & $(0.74,1.30)$ & 46 & 1.08 & $(0.71,1.64)$ \\
\hline Duration (per 5-year increment) & 188 & 136 & 0.96 & $(0.91,1.02)$ & 46 & 1.00 & $(0.93,1.09)$ \\
\hline \multicolumn{8}{|l|}{ Cumulative exposure } \\
\hline $0.01-226.95$ & 94 & 82 & 1.17 & $(0.83,1.66)$ & 22 & 0.97 & $(0.57,1.67)$ \\
\hline $226.96-588.00$ & 42 & 27 & 0.86 & $(0.51,1.46)$ & 15 & 1.57 & $(0.81,3.04)$ \\
\hline$>588.00$ & 52 & 28 & 0.68 & $(0.40,1.17)$ & 9 & 0.85 & $(0.38,1.90)$ \\
\hline $\mathrm{p}$ for trend & & & 0.16 & & & 0.85 & \\
\hline \multicolumn{8}{|l|}{ PAHs from petroleum } \\
\hline Ever exposed & 518 & 390 & 1.01 & $(0.84,1.22)$ & 126 & 1.03 & $(0.78,1.36)$ \\
\hline Duration (per 5-year increment) & 518 & 390 & 1.00 & $(0.97,1.04)$ & 126 & 1.02 & $(0.97,1.07)$ \\
\hline \multicolumn{8}{|l|}{ Cumulative exposure } \\
\hline $0.01-240.50$ & 266 & 209 & 1.04 & $(0.83,1.30)$ & 69 & 1.12 & $(0.81,1.55)$ \\
\hline $240.51-901.00$ & 120 & 87 & 0.89 & $(0.65,1.22)$ & 28 & 0.90 & $(0.56,1.44)$ \\
\hline$>901.00$ & 130 & 93 & 1.05 & $(0.77,1.45)$ & 28 & 0.93 & $(0.58,1.49)$ \\
\hline $\mathrm{p}$ for trend & & & 0.92 & & & 0.63 & \\
\hline \multicolumn{8}{|l|}{ PAHs from wood } \\
\hline Ever exposed & 42 & 37 & 1.11 & $(0.65,1.89)$ & 13 & 1.37 & $(0.65,2.89)$ \\
\hline Duration (per 5-year increment) & 42 & 37 & 1.07 & $(0.96,1.20)$ & 13 & 1.01 & $(0.85,1.21)$ \\
\hline \multicolumn{8}{|l|}{ Cumulative exposure } \\
\hline $0.01-450.00$ & 21 & 16 & 1.02 & $(0.50,1.08)$ & 8 & 1.45 & $(0.59,3.58)$ \\
\hline $450.01-1732.50$ & 10 & 4 & 0.64 & $(0.19,2.25)$ & 4 & 1.73 & $(0.43,6.95)$ \\
\hline$<1732.50$ & 11 & 17 & 1.74 & $(0.67,4.56)$ & 1 & 0.50 & $(0.05,4.72)$ \\
\hline $\mathrm{p}$ for trend & & & 0.19 & & & 0.52 & \\
\hline \multicolumn{8}{|l|}{ PAHs from coal } \\
\hline Ever exposed & 57 & 40 & 0.92 & $(0.59,1.44)$ & 17 & 1.09 & $(0.58,2.03)$ \\
\hline Duration (per 5-year increment) & 57 & 40 & 0.93 & $(0.84,1.03)$ & 17 & 0.99 & $(0.87,1.12)$ \\
\hline \multicolumn{8}{|l|}{ Cumulative exposure } \\
\hline $0.01-142.50$ & 30 & 26 & 1.11 & $(0.63,1.96)$ & 10 & 1.27 & $(0.58,2.81)$ \\
\hline $142.51-546.25$ & 12 & 10 & 1.16 & $(0.47,2.83)$ & 4 & 1.13 & $(0.33,3.85)$ \\
\hline$>546.25$ & 15 & 4 & 0.36 & $(0.11,1.12)$ & 3 & 0.71 & $(0.19,2.61)$ \\
\hline $\mathrm{p}$ for trend & & & 0.09 & & & 0.62 & \\
\hline \multicolumn{8}{|l|}{ PAHs from other sources } \\
\hline Ever exposed & 88 & 69 & 0.88 & $(0.60,1.29)$ & 22 & 0.99 & $(0.57,1.75)$ \\
\hline Duration (per 5-year increment) & 88 & 69 & 1.02 & $(0.94,1.09)$ & 22 & 0.97 & $(0.87,1.09)$ \\
\hline
\end{tabular}


Table 3 (continued)

\begin{tabular}{|c|c|c|c|c|c|c|c|}
\hline \multirow[t]{2}{*}{ Exposure } & \multirow[b]{2}{*}{ n Co } & \multicolumn{3}{|c|}{$\begin{array}{l}\text { Low-grade prostate cancer } \\
n=1,488\end{array}$} & \multicolumn{3}{|c|}{$\begin{array}{l}\text { High-grade prostate cancer } \\
n=436\end{array}$} \\
\hline & & $\mathrm{n} \mathrm{Ca}$ & $\mathrm{OR}^{\mathrm{a}}$ & $95 \% \mathrm{Cl}$ & $\mathrm{nCa}$ & $\mathrm{OR}^{\mathrm{a}}$ & $95 \% \mathrm{Cl}$ \\
\hline \multicolumn{8}{|c|}{ Cumulative exposure } \\
\hline $0.01-200.00$ & 44 & 29 & 0.83 & $(0.50,1.37)$ & 12 & 1.09 & $(0.54,2.19)$ \\
\hline $200.01-725.00$ & 21 & 15 & 0.75 & $(0.37,1.53)$ & 4 & 0.66 & $(0.21,2.07)$ \\
\hline$>725.00$ & 23 & 25 & 1.18 & $(0.59,2.38)$ & 6 & 1.14 & $(0.39,3.34)$ \\
\hline$p$ for trend & & & 0.55 & & & 0.97 & \\
\hline
\end{tabular}

Abbreviations: PAHs Polycyclic aromatic hydrocarbons, CI Confidence interval, OR Odds ratio, Ca Cases, Co Controls

${ }^{a}$ OR adjusted for age, ancestry, education, alcohol drinking, cigarette smoking, body mass index, consumption of fried or grilled food, occupational exposure to benzene, farming, and workplace environmental tobacco smoke

For 903 cases (47\%) we were able to follow-up, we also had information on the Gleason score derived from prostatectomy. Prioritizing prostatectomy scores over those from biopsies led to a confirmation of $94 \%$ and $85 \%$ of non-aggressive and aggressive cancers, respectively, according to our pre-established cut-points. Based on this, no major changes in risk estimates for associations with PAHs were observed compared with those based on biopsy results only. A slight excess in risk could still be observed in association with cumulative exposure to PAHs from wood (data not shown).

Sensitivity analyses excluding controls not recently screened for prostate cancer (see Additional files 3 and 4) or applying alternative weights to intensity categories (data not shown) generated results consistent with our main findings.

\section{Discussion}

Our results provide weak support to the hypothesis that occupational exposure to PAHs is associated with prostate cancer risk. Small excesses in risk were apparent in relation with duration and the highest levels of exposure to PAHs from wood, while remote exposures appeared to be especially associated with high-grade cancers.

Benzo $[a]$ pyrene and several industries entailing high exposure to mixtures of PAHs containing benzo[a]pyrene have been classified as carcinogenic to humans for sites other than the prostate [10]. Very few studies to date have examined the role of specific occupational exposures in prostate cancer risk, including PAHs, precluding drawing definitive conclusions. Nevertheless, the sole cohort study and three case-control studies investigating this association are informative as exposure to PAHs was based on strong exposure assessment protocols and potential confounding was accounted for, although most of these relied on small samples [13-16].

As in our study, all of the case-control studies of prostate cancer conducted to date have examined the role of PAHs from any source, as well as according to their source material [14-16]. While there is, to our knowledge, no evidence that the carcinogenic potential of PAHs would differ according to their source, the latter can reflect, as is the case here for PAHs from wood, exposure circumstances within specific occupations (e.g. firefighters). By contrast, the one cohort study of prostate cancer assessing exposure to PAHs did not distinguish their sources [13].

In our study, other than for the weak signal for an association with PAHs from wood, there was generally no association between exposure to benzo[a]pyrene and other PAHs, and overall prostate cancer risk. An American case-control study observed no association with ever exposure to the same PAHs grouping than us, although benzo[ $a]$ pyrene was not examined [15]. While some increases in risk of overall prostate cancer have been linked to low exposure levels to benzo[a]pyrene $[14,16]$, PAHs from coal $[14,16]$ and PAHs from other sources [16], results for high exposure levels were consistent with no association with these PAHs $[14,16]$, but also those from petroleum, wood [16] and more globally to PAHs from any source $[13,14,16]$.

Our study is the first to investigate associations between PAHs and prostate cancer aggressiveness, defined by tumor histological grade. Previous work suggests that aggressive cancers may have a different set of risk factors, including occupational [19], than their non-aggressive counterpart [27], and that they may have distinct aetiologies [28]. No formal statistical heterogeneity in risk emerged between low- and high-grade cancers, possibly reflecting a lack of statistical power to detect differences (there were fewer highgrade tumors and CIs were wider). In one previous study assessing occupational exposure to PAHs and the degree of spreading of the tumor at diagnosis, no association emerged [13].

Exposure to PAHs from wood mostly occurred in firefighting occupations. A higher prostate cancer 
screening rate in firefighters, as compared to other workers, could have resulted in a positive association with exposure in this group of workers. There is indeed evidence that screening patterns differ according to occupation [29]. However, there was no evidence in our study that firefighters were screened more frequently than other workers (data not shown). Firefighting occupations have been reported at elevated risk of prostate cancer in several studies [30] including in the present study population [17]. Exposure to PAHs, which was not measured in these studies, might explain the excesses in risk, and/or possibly, nightshift work. However, we recently documented the absence of an association between nightshift work and prostate cancer in the PROtEuS study [18], and consequently have not adjusted for this in our models.

Incomplete wood combustion is an important source of benzo[a]pyrene but also of other PAHs such as dibenz[a,h]anthracene, a probable human carcinogen [10]. We found no association with benzo[a]pyrene or with other groups of PAHs that likely contain this chemical.

Cigarette smoking was weakly correlated with occupational exposure to PAHs (data not shown). The strongest correlation was between cigarette smoking and PAHs from petroleum $(r=0.10)$. All correlation coefficients between fried or grilled food consumption and PAHs were close to the null value. These observations argue against a potential over-adjustment for these factors.

There is evidence that PAHs could be genotoxic to the prostate gland through the local formation of PAH-DNA adducts [31]. An interaction between high occupational exposure to $\mathrm{PAHs}$ and the glutathione S-transferase polymorphism (GSTP1), a detoxifying gene, has been shown to be associated with an increased prostate cancer risk [15]. Variants of this gene are known to be involved in the early process of carcinogenesis in prostate gland [32]. Others also reported that the combination of nonfunctionnal GSTP polymorphisms [33] or the presence of GSTP1 methylation in prostate tissue [34] were predisposing factors for prostate cancer.

This study has some limitations. There inevitably was exposure misclassification, probably attenuating risk estimates. While this is the largest study to date, based on the number of exposed cases, conducted on this subject, it may have been underpowered to detect weaker associations, especially in sub-group analyses. Exposure assessment was not conducted for jobs lasting less than 2 years, although this resulted in less than $4 \%$ of work-years, on average, not being covered [35]. Finally, response rates, albeit typical to those encountered in similar community-based studies [36], were good for cases but moderate for controls. Comparisons of areabased indicators (unemployment, education, \% of recent immigrants, income) between participants and nonparticipants showed little differences, reassuring against strong selection bias.

The study also builds on several strengths. The statistical power calculated when designing PROtEuS was quite good, allowing for the detection of moderate associations. Exposure assessment was conducted by expert review, which enables consideration of jobspecific details and idiosyncrasies. This has long been considered to be the reference approach for community-based retrospective studies [37, 38]. We further improved on the transparency of the coding by applying a hybrid approach to guide the experts [23]. PAHs exposures were studied together as well as according to their material source, thereby capturing more specific exposure circumstances. Though residual confounding remains possible, we controlled for factors and occupational agents suspected to be associated with prostate cancer. Other factors included in the models are those that might also include PAHs exposure, such as cigarette smoking and consumption of fried or grilled food. We investigated their correlation with PAHs exposures using Spearman correlation and Kendall's tau-b correlation (data not shown). Cigarette smoking was weakly correlated with occupational exposure to PAHs. The strongest correlation was between cigarette smoking and PAHs from petroleum $(r=0.10)$. All correlation coefficients between fried or grilled food consumption and PAHs were close to the null value. These observations argue against a potential over-adjustment by these factors.

Sensitivity analyses showed consistent results with those from the main analyses. Unlike other previous investigations, we had information on prostate cancer grade, enabling to evaluate associations by cancer aggressiveness. Histology from biopsy categorised into Gleason score is considered to be the 'gold standard' for the diagnosis of prostate cancer [39], and is commonly used to stratify the risk of men and to choose their consecutive treatment. Radical prostatectomy, when indicated, is often deferred for several weeks after biopsy [40]. In some cases, there is a discrepancy between biopsy and prostatectomy Gleason scores, characterized by the upgrading or under-grading of prostate cancer on biopsies. Here, prioritizing findings from prostatectomies resulted in classification changes for $6 \%$ of the initial non-aggressive cancer cases and $15 \%$ of the aggressive ones, but results remained similar to the main findings. And finally, we had information on prostate cancer screening practices and accounted for these in our analyses. Our 
study population is quite unique in that respect. While there was no prostate cancer screening program in place at the time of study, screening tests were often part of annual medical routine exams in this population, which has universal and free access to healthcare. The lack of considering detection issues in epidemiological studies of prostate cancer has been recognized as a salient problem that may have obscured associations and hampered progress in identifying risk factors for this cancer [41, 42].

\section{Conclusion}

Overall, our results provide weak support to the hypothesis that occupational exposure to PAHs is associated with prostate cancer risk.

\section{Supplementary Information}

The online version contains supplementary material available at https://doi. org/10.1186/s12940-021-00751-w.

Additional file 1: Table S1. Most Frequent* Occupations Classified as Having Probable or Definite Occupational Exposure to Polycyclic Aromatic Hydrocarbons (PAHs), PROtEuS, Montreal, 2005-2012.

Additional file 2: Figure. Spearman Correlation's Coefficients Between Cumulative Exposure to Polycyclic Aromatic Hydrocarbons From Various Sources Among Controls, PROtEuS, Montreal, Canada, 2005-2012.

Additional file 3: Table S2. Association Between Occupational Exposure to PAHs and Prostate Cancer Risk, Restricting Controls to Men Screened for Prostate Cancer in the Two Years Prior to Interview, PROtEuS, Montreal, Canada, 2005-2012.

Additional file 4: Table S3. Association Between Occupational Exposure to PAHs and Prostate Cancer Risk, by Tumor Aggressiveness, Restricting Controls to Men Screened for Prostate Cancer in the Two Years Prior to Interview, PROtEuS, Montreal, Canada, 2005-2012.

\section{Acknowledgements}

The authors would like to thank all members of the Epidemiology and Biostatistics Unit at INRS-Centre Armand-Frappier Santé Biotechnologie who were involved in the conduct of the study. In particular, we want to highlight the work of Louise Nadon, Ramzan Lakhani, Mounia Senhaji Rhazi and Robert Bourbonnais, who carried out the occupational exposure assessment. The contribution of Hughes Richard in the preparation of the databases is also gratefully acknowledged. We thank the urologists from the participating hospitals for their collaboration in patients' access.

\section{Authors' contributions}

CB conducted the data analysis and prepared the manuscript. MEP conceived and led the PROtEuS study. CB and MEP contributed to the interpretation of the data and critically revised the manuscript. All authors read and approved the final version of the manuscript.

\section{Funding}

This study was supported financially through grants from the Canadian Cancer Society (grants no. 13149, 19500, 19864 and 19865), the Cancer Research Society, the Fonds de Recherche du Québec-Santé (FRQS), FRQS-Réseau de recherche en santé environnementale and the Ministère du Développement économique, de l'Innovation et de l'Exportation du Québec, and the Canadian Institutes of Health Research (grant no. 159704). MEP received career awards from the FRQS, CB was supported from postdoctoral fellowships from Prostate Cancer Canada and from the Fondation Armand-Frappier.

\section{Availability of data and materials}

The data that support the findings of this study are available from the corresponding author upon request that meet confidentiality agreement with study subjects.

\section{Declarations}

\section{Ethics approval and consent to participate}

Comité d'éthique et de la recherche - Institut national de la recherche scientifique, and all hospitals where cases were ascertained. Each participant provided written informed consent.

\section{Consent for publication}

Not applicable.

\section{Competing interests}

The authors declare that they have no competing interests.

\section{Author details}

'Epidemiology and Biostatistics Unit, Centre Armand-Frappier Santé Biotechnologie, Institut national de la recherche scientifique, Université du Québec, 531 Boulevard des Prairies, Laval, Québec H7V 1B7, Canada. ${ }^{2}$ Department of Social and Preventive Medicine, School of Public Health, Université de Montréal, Montréal, Québec, Canada. ${ }^{3}$ University of Montreal's Hospital Research Centre, Montréal, Québec, Canada.

Received: 18 March 2021 Accepted: 23 May 2021

Published online: 21 June 2021

\section{References}

1. Bray F, Ferlay J, Soerjomataram I, Siegel RL, Torre LA, Jemal A. Global cancer statistics 2018: GLOBOCAN estimates of incidence and mortality worldwide for 36 cancers in 185 countries. CA Cancer J Clin. 2018;68(6):394-424.

2. Forman D, Bauld L, Bonanni B, Brenner H, Brown K, Dillner J, et al. Time for a European initiative for research to prevent cancer: a manifesto for Cancer Prevention Europe (CPE). J Cancer Policy. 2018;17:15-23.

3. Martini F, Timmons MJ, Tallitsch RB. Human anatomy. 7th ed. Boston: pearson benjamin cummings; 2012. p. 870.

4. Klassen AC, Platz EA. What can geography tell us about prostate cancer? Am J Prev Med. 2006;30(2):S7-15.

5. Hsing AW, Devesa SS. Trends and patterns of prostate cancer: what do they suggest? Epidemiol Rev. 2001;23(1):3-13.

6. Lee J, Demissie K, Lu S-E, Rhoads GG. Cancer incidence among KoreanAmerican immigrants in the United States and native Koreans in South Korea. Cancer Control. 2007;14(1):78-85.

7. DeRosa C, Richter P, Pohl H, Jones DE. Environmental exposures that affect the endocrine system: public health implications. J Toxicol Environ Health Part B. 1998;1 (1):3-26.

8. Kirkland D, Kasper P, Martus H-J, Müller L, van Benthem J, Madia F, et al. Updated recommended lists of genotoxic and non-genotoxic chemicals for assessment of the performance of new or improved genotoxicity tests. Mutat Res Toxicol Environ Mutagen. 2016;795:7-30.

9. Lima ALC, Farrington JW, Reddy CM. Combustion-derived polycyclic aromatic hydrocarbons in the environment-a review. Environ Forensics. 2005;6(2):109-31.

10. IARC Working Group on the Evaluation of Carcinogenic Risks to Humans. Some non-heterocyclic polycyclic aromatic hydrocarbons and some related exposures. IARC Monogr Eval Carcinog Risks Hum. 2010;92:1-853.

11. Moorthy B, Chu C, Carlin DJ. polycyclic aromatic hydrocarbons: from metabolism to lung cancer. Toxicol Sci. 2015;145(1):5-15.

12. Piskorska-Pliszczynska J, Keys B, Safe S, Newman MS. The cytosolic receptor binding affinities and $\mathrm{AHH}$ induction potencies of 29 polynuclear aromatic hydrocarbons. Toxicol Lett. 1986;34(1):67-74.

13. Boers D. The influence of occupational exposure to pesticides, polycyclic aromatic hydrocarbons, diesel exhaust, metal dust, metal fumes, and 
mineral oil on prostate cancer: a prospective cohort study. Occup Environ Med. 2005;62(8):531-7.

14. Aronson KJ, Siemiatycki J, Dewar R, Gerin M. Occupational risk factors for prostate cancer: results from a case-control study in Montreal, Quebec. Canada Am J Epidemiol. 1996;143(4):363-73.

15. Rybicki BA, Neslund-Dudas C, Nock NL, Schultz LR, Eklund L, Rosbolt J, et al. Prostate cancer risk from occupational exposure to polycyclic aromatic hydrocarbons interacting with the GSTP1 lle105Val polymorphism. Cancer Detect Prev. 2006;30(5):412-22.

16. Nadon L, Siemiatycki J, Dewar R, Krewski D, Gérin M. Cancer risk due to occupational exposure to polycyclic aromatic hydrocarbons. Am J Ind Med. 1995;28(3):303-24.

17. Sauvé J-F, Lavoué J, Parent M-É. Occupation, industry, and the risk of prostate cancer: a case-control study in Montréal, Canada. Environ Health. 2016;15(1):100.

18. Barul C, Richard H, Parent M-E. Night-shift work and risk of prostate cancer: results from a canadian case-control study, the prostate cancer and environment study. Am J Epidemiol. 2019;188(10):1801-11.

19. Blanc-Lapierre A, Sauvé J-F, Parent M-E. Occupational exposure to benzene, toluene, xylene and styrene and risk of prostate cancer in a population-based study. Occup Environ Med. 2018;75(8):562-72.

20. Department of Employment and Immigration. Canadian Classification Dictionary of Occupations, vol. 1. Ottawa: Department of Employment and Immigration; 1971.

21. Statistics Canada, Standards Division. Statistics Canada. Ottawa: Standard Industrial Classification; 1980.

22. Swanson GP, Trevathan S, Hammonds KAP, Speights VO, Hermans MR. Gleason score evolution and the effect on prostate cancer outcomes. Am J Clin Pathol. 2021;155(5):711-7.

23. Sauvé J-F, Lavoué J, Nadon L, Lakhani R, SenhajiRhazi M, Bourbonnais R, et al. A hybrid expert approach for retrospective assessment of occupational exposures in a population-based case-control study of cancer. Environ Health. 2019;18(1):14.

24. Lavoué J, Pintos J, Van Tongeren M, Kincl L, Richardson L, Kauppinen T, et al. Comparison of exposure estimates in the Finnish job-exposure matrix FINJEM with a JEM derived from expert assessments performed in Montreal. Occup Environ Med. 2012;69(7):465-71.

25. Wright JL, Salinas CA, Lin DW, Kolb S, Koopmeiners J, Feng Z, et al. Prostate cancer specific mortality and gleason 7 disease differences in prostate cancer outcomes between cases with gleason $4+3$ and gleason 3 + 4 tumors in a population based cohort. J Urol. 2009;182(6):2702-7.

26. Shih $\mathrm{H}-J$, Fang $\mathrm{S}-\mathrm{C}$, An L, Shao Y-HJ. Early-onset prostate cancer is associated with increased risks of disease progression and cancer-specific mortality. Prostate. 2021;81(2):118-26.

27. Demoury C, Karakiewicz P, Parent M-E. Association between lifetime alcohol consumption and prostate cancer risk: a case-control study in Montreal. Canada Cancer Epidemiol. 2016:45:11-7.

28. VanderWeele DJ, Brown CD, Taxy JB, Gillard M, Hatcher DM, Tom WR, et al. Low-grade prostate cancer diverges early from high grade and metastatic disease. Cancer Sci. 2014;105(8):1079-85.
29. Peters CE, Villeneuve PJ, Parent M-É. Occupation as a predictor of prostate cancer screening behaviour in Canada. J Med Screen. 2020;27(4):215-22. https://doi.org/10.1177/096914132090248.

30. Sritharan J, Pahwa M, Demers PA, Harris SA, Cole DC, Parent M-E. Prostate cancer in firefighting and police work: a systematic review and metaanalysis of epidemiologic studies. Environ Health Glob Access Sci Source. 2017;16(1):124

31. Tang D, Kryvenko ON, Wang Y, Jankowski M, Trudeau S, Rundle A, et al. Elevated polycyclic aromatic hydrocarbon-DNA adducts in benign prostate and risk of prostate cancer in African Americans. Carcinogenesis. 2013;34(1):113-20.

32. Costa VL, Henrique R, Jerónimo C. Epigenetic markers for molecular detection of prostate cancer. Dis Markers. 2007;23(1-2):31-41.

33. Srivastava DSL, Mandhani A, Mittal B, Mittal RD. Genetic polymorphism of glutathione S-transferase genes (GSTM1, GSTT1 and GSTP1) and susceptibility to prostate cancer in Northern India. BJU Int. 2005;95(1):170-3.

34. Goering W, Kloth M, Schulz WA. DNA Methylation Changes in Prostate Cancer. In: Dumitrescu RG, Verma M, éditeurs. Cancer Epigenetics [Internet]. Totowa, NJ: Humana Press; 2012. p. 47-66. Disponible sur: http://link. springer.com/https://doi.org/10.1007/978-1-61779-612-8_4

35. Parent M-É, Richard H, Sauvé J-F. Characterizing Short-Term Jobs in a Population-Based Study. Ann Work Expo Health. 2019;63(6):701-5.

36. Xu M, Richardson L, Campbell S, Pintos J, Siemiatycki J. Response rates in case-control studies of cancer by era of fieldwork and by characteristics of study design. Ann Epidemiol juin. 2018;28(6):385-91.

37. Bouyer J, Hemon D. Retrospective evaluation of occupational exposures in population-based case-control studies: general overview with special attention to job exposure matrices. Int J Epidemiol. 1993;22(Supplement 2):S57-64.

38. Teschke K. Occupational exposure assessment in case-control studies: opportunities for improvement. Occup Environ Med. 2002;59(9):575-94.

39. Mottet N, Bellmunt J, Bolla M, Briers E, Cumberbatch MG, De Santis M, et al. EAU-ESTRO-SIOG guidelines on prostate cancer. part 1: screening, diagnosis, and local treatment with curative intent. Eur Urol. 2017;71(4):618-29.

40. Sokoloff MH, Brendler CB. Indications and contraindications for nervesparing radical prostatectomy. Urol Clin North Am. 2001;28(3):535-43.

41. Garcia-Closas M, Berrington de Gonzalez A. Invited commentary: screening and the elusive etiology of prostate cancer. Am J Epidemiol. 2015;182(5):390-3.

42. Weiss NS. Adjusting for screening history in epidemiologic studies of cancer: why, when, and how to do it. Am J Epidemiol. 2003;157(11):957-61.

\section{Publisher's Note}

Springer Nature remains neutral with regard to jurisdictional claims in published maps and institutional affiliations.

Ready to submit your research? Choose BMC and benefit from:

- fast, convenient online submission

- thorough peer review by experienced researchers in your field

- rapid publication on acceptance

- support for research data, including large and complex data types

- gold Open Access which fosters wider collaboration and increased citations

- maximum visibility for your research: over $100 \mathrm{M}$ website views per year

At BMC, research is always in progress.

Learn more biomedcentral.com/submissions 